Article

\title{
Freeze-Drying with Structured Sublimation Fronts-Visualization with Neutron Imaging
}

\author{
Nicole Vorhauer-Huget ${ }^{1, *}$, David Mannes ${ }^{2}$, Mathias Hilmer ${ }^{3}(0)$, Sebastian Gruber ${ }^{3}$, \\ Markus Strobl ${ }^{2} \mathbb{D}$, Evangelos Tsotsas ${ }^{1}$ and Petra Foerst ${ }^{3} \mathbb{D}$ \\ 1 Institute of Process Engineering, Otto von Guericke University Magdeburg, 39106 Magdeburg, Germany; \\ evangelos.tsotsas@ovgu.de \\ 2 Laboratory for Neutron Scattering and Imaging, Paul Scherrer Institute, 5232 Villigen, Switzerland; \\ david.mannes@psi.ch (D.M.); markus.strobl@psi.ch (M.S.) \\ 3 Chair of Process Systems Engineering, Technical University of Munich, 80333 München, Germany; \\ mathias.hilmer@tum.de (M.H.); sebi.gruber@tum.de (S.G.); petra.foerst@tum.de (P.F.) \\ * Correspondence: nicole.vorhauer-huget@ovgu.de; Tel.: +49-391-675-1684
}

Received: 31 July 2020; Accepted: 30 August 2020; Published: 2 September 2020

\begin{abstract}
The particular structure of the sublimation front in vacuum freeze-drying of porous media is, in most situations, not accessible at the pore scale. The classical measurement techniques access the process only globally. Knowledge about the structure of the front, however, is necessary for prescriptive analysis of freeze-drying, as it dictates not only drying velocity, drying time, and overall energy consumption, but also the material properties after drying. This is especially relevant in situations in which the freeze-drying process is carried out close to the collapse temperature of the product. We, therefore, study the sublimation of ice with neutron tomography and analyze the spatial formation of the dry space using the example of frozen cylindrical maltodextrin with drying parameters at the limit of material collapse. We show that the sublimation front forms unique fractal structures that differ strongly from the usual form of a flat front. Distinct dry fingers covering the sample, in addition to a fractal peripheral sublimation front, were observed. The findings are important for the understanding of freeze-drying processes and will serve as a basis for the development of microscale models of freeze-drying.
\end{abstract}

Keywords: neutron tomography; image analysis; freeze-drying; drying front; front structure

\section{Introduction}

Vacuum freeze-drying is frequently applied for high-value products, such as pharmaceuticals, biological products, and food [1-6]. It is carried out at temperatures and pressures below the triple point of water in order to avoid undesirable capillary effects that would otherwise be associated with the transport of liquid water, e.g., shrinking of the material. At the same time, the drying products are conserved at low temperatures, avoiding biological deterioration or other effects such as color change, loss of flavor, or decomposition of ingredients. Due to the application of low temperatures, freeze-drying is indeed a very gentle method to remove moisture from products; however, at the same time, it is very slow with comparably low throughput and high energy consumption. Understandably, it is one of the major issues to minimize the duration of freeze-drying processes, but without compromising product quality.

An increase in drying rate is naturally achieved via an increase in heat flux, which is supplied for the sublimation of frozen water. However, the increase in temperature at higher heat flow rates is very likely to cause product damage, if the glass transition temperature of the solid material or the melting point of water is locally exceeded inside the frozen product [7-9]. Consequently, the aspired 
product quality achieved via the prevention of local material collapse represents the upper limit for heat supply, temperature, and drying rate.

In more detail, the temperature distribution inside the frozen material, as well as the drying rates, depends on the heat transfer kinetics through it. However, the kinetics can vary locally since the product is essentially a mixture of frozen water, frozen solid, and dried empty pores. At the same time, the material composition and, thus, the local heat and mass transfer properties change continuously due to the progress of the sublimation front during drying. While frozen water has a relatively high thermal conductivity $\left(2.2 \mathrm{~W} \cdot \mathrm{m}^{-1} \cdot \mathrm{K}^{-1}\right)$, the thermal conductivity of the dried regions can be orders of magnitude smaller. This can have severe effects if the product contains a broad distribution of pore sizes. Exemplarily, local overheating and a localized increase in temperature above the critical point can occur if the larger pores dry faster than their smaller neighbors. Thus, shortly, the conflict here is to increase drying rates within the given constraints of temperature control.

The tradeoff among product quality, throughput, and overall energy consumption is usually found based on macroscopic measurements of temperature and pressure [10-13]. Since the process is strongly influenced by the internal structure of the frozen product and local distribution of ice, solid, and voids, information on the microscale would instead be required to optimize process control $[14,15]$. One possibility to obtain the required microscale information of the freeze-drying process is the use of imaging and other techniques with a high spatial resolution, such as micro-computed tomography, magnetic resonance imaging (MRI), nuclear magnetic resonance (NMR), lyo-microscopy, and scanning electron microscopy (SEM) [16-20]. So far, only a few examples exist where spatial pore-scale variations of the structure were investigated [7,20-22]. Nevertheless, a major constraint of imaging techniques is generally the accessibility of the process during operation, i.e., the acquisition of in operando data. The aim of current research, thus, is to explore possible alternative routes for the characterization of freeze-drying processes using these techniques. Exemplarily, Siebert et al. [20] showed via micro-computed tomography of a partially freeze-dried piece of a carrot that the vascular tissue, with large lamellar pores penetrating the carrot piece from top to bottom, dries faster than the surrounding tissue with significantly smaller pores. Siebert et al. [20] observed that drying occurred from the center, with the formation of intermediate fractal dry fingers which were surrounded by an ice ring. The authors concluded that the progress of freeze-dying must be different to literature theory, where the ingress of sublimation occurs from the bottom toward the top or vice versa depending on the process conditions $[1,6,23]$. The formation of a flat front, as a consequence of the co-current heat and vapor fluxes, and with the result of the development of a growing homogeneous dry zone (Figure 1a), was not observed in their case. Instead, a much more complex drying behavior was found due to the heterogeneous structure of the tissue. Similarly, Nakagawa et al. [24] found that unique sublimation zones can occur in frozen dextrin solution. The significance of the structure was explained based on the sample preparation with and without annealing, the drying rate, and the glassy phase. It was found that the fractal sublimation fronts were a result of fast freezing and omitted annealing prior to drying. The thin and soft pore walls allowed for structure deformation when the water was removed. The X-ray computed tomography images of Nakagawa et al. [24] revealed extremely large pores in the non-annealed samples. This again affected the formation of the sublimation front, which was again not flat but with distinct fractal characteristics.

These examples reveal not only the importance but also the potential of microscale studies of freeze-drying, especially if the visualization can be carried out continuously during the process or at least at intermittent time intervals.

In this paper, we present and discuss the application of neutron imaging for the continuous visualization of sublimation on the microscale in a fully equipped environment. Neutron imaging is a noninvasive, nondestructive measurement technology that allows in situ visualization. On the basis of the high attenuation coefficient of hydrogen, neutron imaging is a very sensitive tool to detect water during freeze-drying [25]. The attenuation coefficients of other materials, such as carbon or metals, are much lower. Neutron imaging is, therefore, very suitable for measurements in fully equipped 
set-ups [26-28]. Although the resolution is rather low compared to X-ray micro tomography, water detection is much more reliable due to the achieved contrast between the materials, particularly in a complex sample environment which would be impermeable for X-rays. This enables the visualization of distinct structures of the sublimation front in the fully equipped freeze-dryer.

Our research aims at a better understanding of the dominant effects that control drying kinetics and product quality. The focus of this paper is, therefore, on the structure of the sublimation front developed during primary freeze-drying of a cylindrical block of frozen maltodextrin, a polysaccharide often used as a food stabilizer or pharmaceutical excipient. We present the experimental set-up with which the study was realized and show and discuss the images obtained from neutron tomography of the partially dried block. In particular, the complex transient structure of the sublimation front is described in this paper. It is discussed in comparison to drying with a flat sublimation front (Figure 1), as well as based on the impact of freezing and drying conditions.

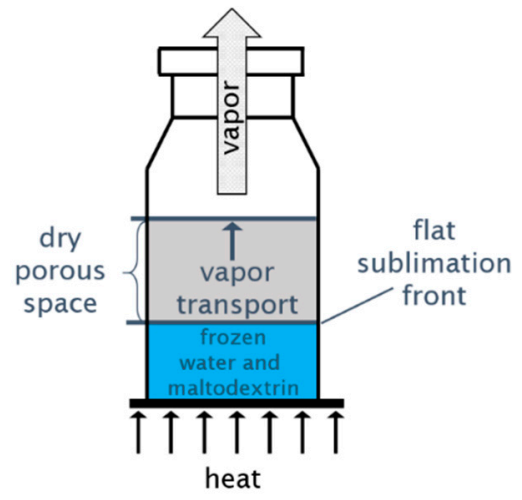

(a)

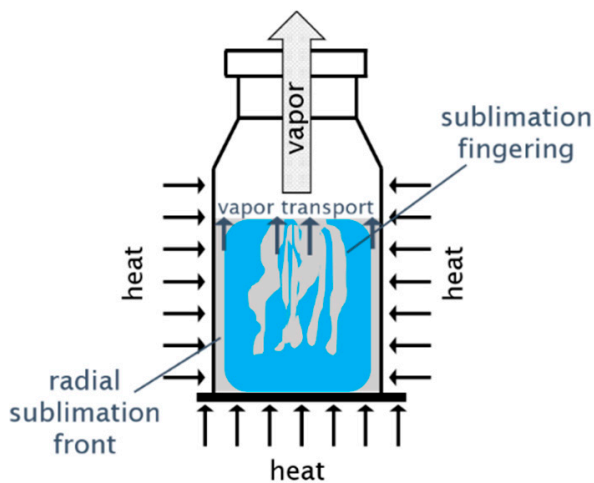

(b)

Figure 1. (a) Freeze-drying of liquid solutions with a flat sublimation front that travels from top to bottom during drying. (b) Heterogeneous sublimation with the formation of distinct structures and different sublimation zones.

\section{Materials and Methods}

\subsection{Experimental Equipment and Parameters}

The drying experiment was realized in a climate chamber of size $160 \times 160 \times 160 \mathrm{~mm}^{3}$ [27], which was cooled by two Peltier elements. It was equipped with an individually designed depressurized cylindrical aluminum drying chamber with an inner diameter of $25.5 \mathrm{~mm}$, outer diameter of $28.75 \mathrm{~mm}$, and height of $30 \mathrm{~mm}$, mounted on a rotating plate in the center of the climate chamber (Figure 2). The design of the drying chamber was selected analogous to typical designs used in pharmaceutical production processes, e.g., from GEA Germany, with inner diameters between $15 \mathrm{~mm}$ and $30 \mathrm{~mm}$. However, instead of glass, we used aluminum for the purpose of neutron imaging [25].

In this paper, we present and discuss only the morphological peculiarities of one experiment with the focus on the structure of the sublimation front. The complete drying process was carried out in the set-up shown in Figure 2. However, we present here only the tomography images after $11.5 \mathrm{~h}$ of drying, i.e., the transient sublimation front during drying.

Evacuation of the drying chamber was realized with a rotary vane pump (Vacuubrand chemistry hybrid pump RC6 with $6.9 \mathrm{~m}^{3} \cdot \mathrm{h}^{-1}$ suction capacity and $4 \times 10^{-4} \mathrm{mbar}$ final pressure). The pressure was not controlled but measured with a Pirani gauge (Vacuubrand CVC300 with Vacuu View extended; lower measuring limit $10^{-3}$ mbar) inside the exhaust pipe. The exhaust pipe was a plastic pipe with an inner diameter of $40 \mathrm{~mm}$. The Pirani sensor was located around $1.5 \mathrm{~m}$ away from the drying chamber. A long distance was required in order to avoid interaction of the neutron radiation with the technical equipment. The pressure measurement during drying revealed slightly decreasing pressure between 
0.63 mbar and 0.61 mbar. On the basis of the low volume flow rates and the low friction coefficient of the pipe, it can be assumed that the pressure drop between the drying chamber and the Pirani sensor was very small.

Platinum resistance thermometers (Pt-100) were installed inside the climate chamber and the drying chamber to monitor temperatures. The chamber temperature was kept constant at $-5{ }^{\circ} \mathrm{C}$ during drying. The product temperature was not measured but estimated from the correlation of Reference [29]. Assuming a negligible pressure drop between the drying chamber and the Pirani sensor, the product temperature was $-25^{\circ} \mathrm{C}$ on the basis of this correlation. Ergo, with the given parameters, the temperature difference between the drying front and the walls was approximately $20 \mathrm{~K}$.

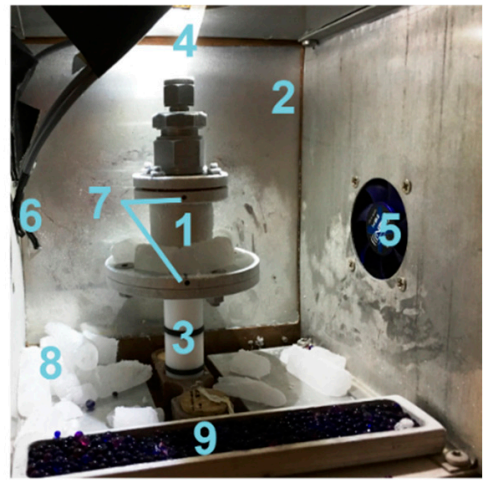

(a)
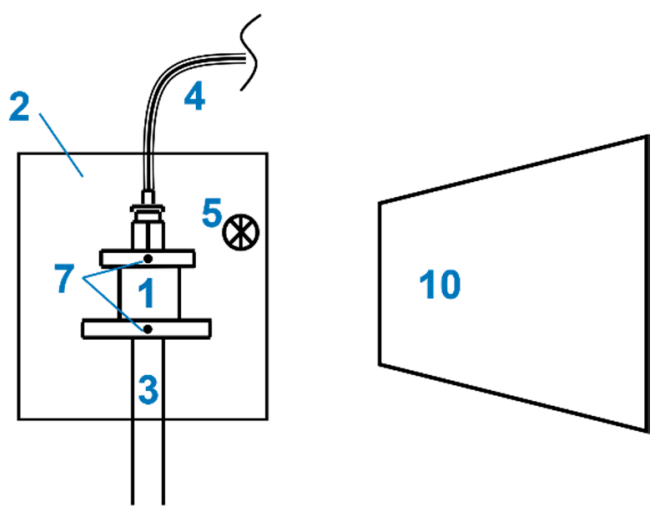

(b)

Figure 2. (a) Picture of the drying chamber mounted on the sample holder inside the climate chamber [27]. (b) Schematic sketch of the set-up. The front door is not shown; 1: drying chamber with sample, 2: climate chamber, 3: rotating sample holder, 4: exhaust pipe to Pirani sensor and vacuum pump, 5: ventilation, 6: Pt-100 thermometers, 7: bore holes for fixation of thermometers (during measurement), 8: dry ice, 9: silica gel, 10: collimator [30].

The whole system was cooled at the end of the measurement (after $11.5 \mathrm{~h}$ ) and the pressure was elevated to 1 bar with the purpose of interrupting sublimation (at colder temperatures) for the tomography scan presented below.

\subsection{Sample Preparation}

We used maltodextrin DE12 Glucidex from Roquette (France) (Table 1). Maltodextrin was solved in deuterium oxide (heavy water, $\mathrm{D}_{2} \mathrm{O}$ ), which has an attenuation coefficient about one order of magnitude lower than $\mathrm{H}_{2} \mathrm{O}$ (neutron attenuation coefficient (at $4.1 \AA$ ) is $0.7 \mathrm{~cm}^{-1}$ for $\mathrm{D}_{2} \mathrm{O}$ and $5.4 \mathrm{~cm}^{-1}$ for $\mathrm{H}_{2} \mathrm{O}$ [31]) and allows for a better contrast between frozen water and the surrounding material in image processing. The change in solvent was expected to have no other major impact on the physics of the drying experiment.

Table 1. Sample preparation parameters.

\begin{tabular}{ccc}
\hline Solid Content $w / w$ & Total Sample Weight $(\mathrm{g})$ & Freezing Temperature $\left({ }^{\circ} \mathrm{C}\right)$ \\
\hline 20 & 4.41 & $-78^{\circ} \mathrm{C}$ \\
\hline
\end{tabular}

The sample was filled in the drying chamber in a liquid state and then frozen inside the drying chamber. The total sample weight given in Table 1 refers to the mass of the liquid solution filled in the drying chamber prior to freezing. We used dry ice for freezing and storing of the sample. The freezing temperature was around $-78^{\circ} \mathrm{C}$ (temperature of the subliming dry ice). Freezing was realized outside the imaging set-up; therefore, the freezing process could not be observed. For this purpose, the liquid-filled drying chamber was moved into a box filled with dry ice. The dry ice was then gently 
placed around the drying chamber. Freezing, thus, occurred undirected from all sides of the sample. However, according to the attachment of the sample to the lateral walls and the bottom, the major freezing direction was radially from the perimeter toward the center and, at the same time, upward from bottom to top. Due to the cylindrical geometry of the sample chamber, the sample was also cylindrical with a diameter of $25.5 \mathrm{~mm}$ and height of approximately $8 \mathrm{~mm}$ after freezing. As discussed below in Section 3.2 the freezing method had a significant impact on the pore structure.

\subsection{Neutron Facility}

The measurement was performed at the cold neutron imaging instrument ICON [30] at the SINQ neutron source of the Paul Scherrer Institute in Villigen, Switzerland [32]. The detection was realized with the Midi-Box [30] and with an Andor ikon-L camera featuring a $2048 \times 2048$ pixel chip. The field of view was $68.79 \times 68.79 \mathrm{~mm}^{2}$ and the pixel size was $33.6 \mu \mathrm{m}$. The scintillator was a $50-\mu \mathrm{m}$-thick $6 \mathrm{LiF}$ : $\mathrm{ZnS}$ screen (from RCTRITEC, Teufen, Switzerland). At the measuring position, an $L / D$ ratio of 343 was yielded [30]. Together with the distance $l$ between sample and detector of approximately $40 \mathrm{~mm}$, a geometrical unsharpness of $u_{g}=l / L / D=117 \mu \mathrm{m}$ can be expected.

\subsection{Tomography}

The tomography scan was conducted after $11.5 \mathrm{~h}$ of drying in order to visualize the transient sublimation front during drying. It consisted of 376 equidistant projections between $0^{\circ}$ and $360^{\circ}$. With an exposure time of $15 \mathrm{~s}$ per projection and waiting time (for rotation, as well as shutter opening and closing) of around $20 \mathrm{~s}$, the whole scan took almost $4 \mathrm{~h}$. The tomography was reconstructed using the Software Octopus by XRE, and the visualization was done with VG Studio max. Subsequently, Kiptool [33] was used on the reconstructed volume dataset for noise reduction.

\section{Results and Discussion}

\subsection{Structure of the Sublimation Front}

Figure 3 shows the in situ (inverse) tomography image of the freeze-dried maltodextrin cylinder after $11.5 \mathrm{~h}$ of drying. The drying process was not finished when the tomography started, such that the sample contained still a significant amount of water, which was not quantified. The image shows the transient structure of the sublimation front with different regions, as explained below.

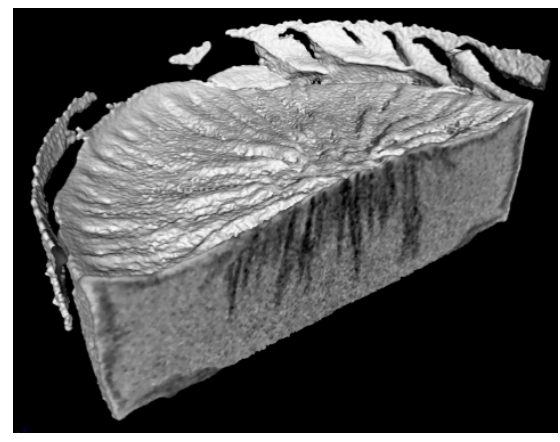

Figure 3. Visualization of the reconstructed three-dimensional (3D) tomography image of the frozen and partially dried maltodextrin sample with vertical cut through the center. The dark fingers penetrating the sample in the center correspond to dry regions.

Firstly, it is clearly visible that the sample itself had a heterogeneous structure. The loose parts at the upper periphery of the sample correspond to detached maltodextrin pieces which might have been a result of sample shrinking during drying (e.g., Reference [9]). However, possible collapse phenomena would have occurred on smaller length and time scales which were not resolved with the utilized neutron imaging technique. Apart from that, it can also be seen that the surface of the sample was not 
flat. It had a concave structure, with greater heights at the periphery and in the center. It is obvious that this shape was a result of the freezing process.

The internal surface is visualized by a vertical cut through the cylindrical cake in Figure 3. It exhibits different gray values, which correspond to different material compositions. As heavy water attenuated neutron radiation, water-saturated regions appear in light gray in the inverse tomography image. Moreover, maltodextrin appears in light gray. In contrast to that, empty regions appear in black (outside of the sample) or in dark gray (inside of the sample). It is, thus, possible to distinguish the dry regions from the water-saturated regions. The different dark-gray regions found inside the sample correspond to different structural peculiarities that are further studied below. The most prominent characteristics are the dark-gray fingers that penetrate the sample in the center. Since these fingers represent the dry zones, they are also named sublimation fingers. The dark-gray regions at the perimeter of the sample in Figure 3 additionally indicate peripheral drying. The shrinkage and deformation of the sample obviously enabled the detachment of the sample from the lateral walls, resulting in an increase of the sublimation interface. As a major result of this, different sublimation zones developed (Figure 4).

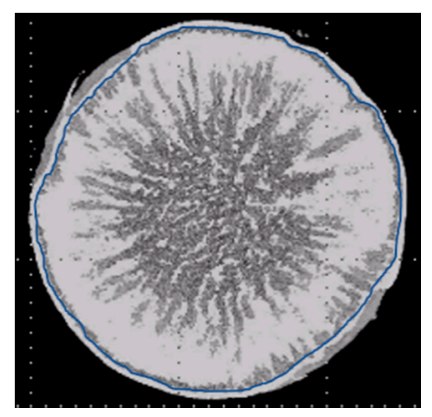

(a)

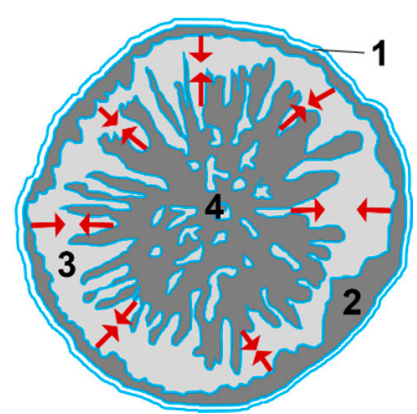

(b)

Figure 4. (a) The horizontal cut through the tomography image of the partially dried sample (after $11.5 \mathrm{~h}$ of drying) reveals the dry zones. The light-gray regions contain water and maltodextrin (it is noted that maltodextrin and heavy water are not distinguished from this image). (b) Schematic illustration of the different zones that are distinguished from the tomography image. The red arrows depict the expansion direction of the dry zones. 1: accumulation of maltodextrin inside the peripheral maltodextrin belt; 2 : peripheral sublimation zone with fractal front; 3 : ring of frozen water and maltodextrin; 4: sublimation fingering zone.

In Figure 4, the most striking observation is clearly the lamellar dark-gray zone in the center of the sample. The sublimation of water obviously resulted in the formation of a large dry region. The region outside of the blue circle in Figure 4a is expected to have a high maltodextrin content and small (dry) pores which are not resolved with the neutron imaging set-up (with a pixel resolution of $33.6 \mu \mathrm{m}$ ). This region is named the peripheral maltodextrin belt. Based on the assumption of a radial temperature gradient with high temperature at the wall and lower temperatures inside the sample, it can strongly be expected that the maltodextrin belt was completely dry. The accumulation of maltodextrin in this region might have been reinforced by material shrinkage and possible collapse phenomena.

Connected to the peripheral maltodextrin belt is the peripheral sublimation zone. It is the zone of peripheral sublimation, characterized by a heterogeneous (fractal) sublimation front. The occurrence of this zone was possible because of the detachment of the sample from the side walls and the possibility of also removing water from the shell surface of the maltodextrin cylinder.

The third region is located between the peripheral sublimation front and the dry fingers in the center of the sample. It is ring-shaped and consists mainly of frozen heavy water and maltodextrin. This region is called the frozen ring. It must have contracted laterally with progression of the peripheral sublimation front and the dry fingers corresponding to the sublimation fingering zone (zone 4) in the 
center of the sample. When the drying experiment was stopped after $11.5 \mathrm{~h}$, the fingers covered a greater fraction of the sample than the peripheral dry region. Continuation of the drying process beyond $11.5 \mathrm{~h}$ would have probably resulted in the merging of the peripheral sublimation zone and the sublimation fingering zone and, thus, the disappearance of the frozen ring.

Figure 5 contains several horizontal cross-sectional images of the sample at different heights. These images were extracted from the 3D volume reconstruction on the basis of the neutron tomographic measurement (Figure 3). Due to the irregular shape of the sample surface, the first two images in Figure 5 mainly show the peripheral edge and the center peak. The sample partly detached from the bottom shelf, most probably due to material shrinkage. This is clearly visible in the last image of Figure 5 (position $0.2 \mathrm{~mm}$ ). Figure 5 further indicates that the sample also dried from the bottom side, where dark-gray regions are visible at position $0.2 \mathrm{~mm}$.

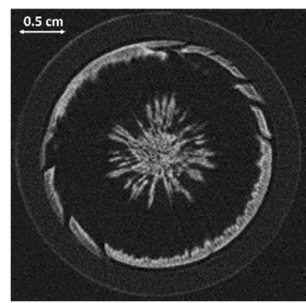

$7.7 \mathrm{~mm}$

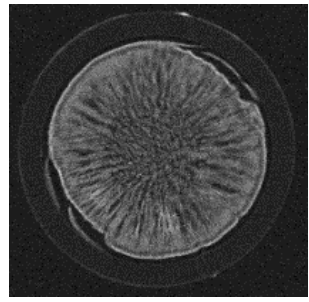

$6.8 \mathrm{~mm}$

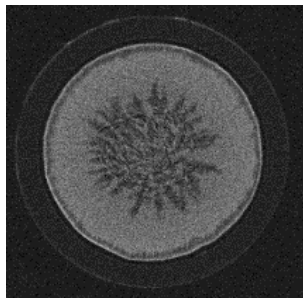

$5.2 \mathrm{~mm}$

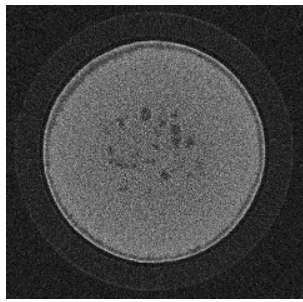

$1.9 \mathrm{~mm}$

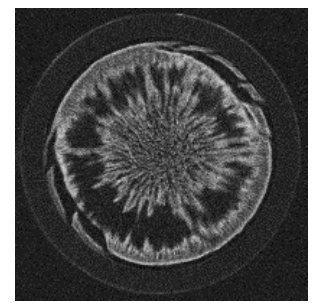

$7.3 \mathrm{~mm}$

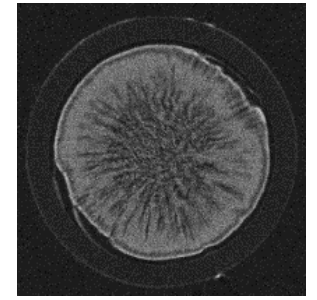

$6.5 \mathrm{~mm}$

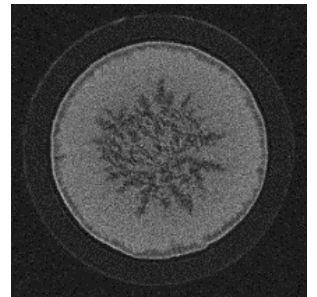

$4.8 \mathrm{~mm}$

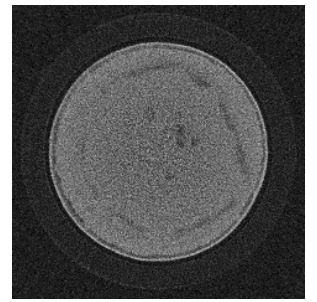

$1.2 \mathrm{~mm}$

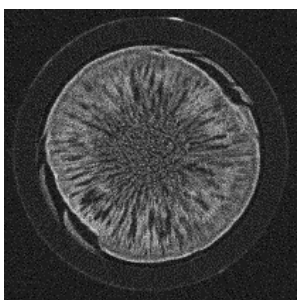

$7.1 \mathrm{~mm}$

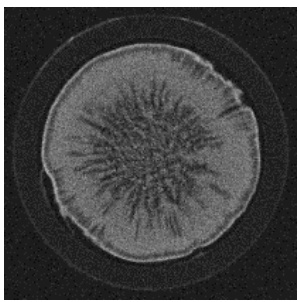

$6.2 \mathrm{~mm}$

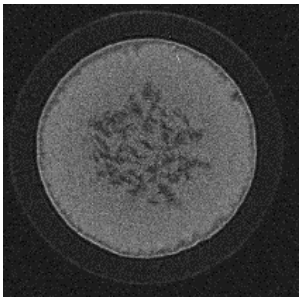

$3.9 \mathrm{~mm}$

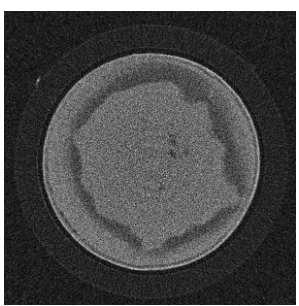

$0.9 \mathrm{~mm}$

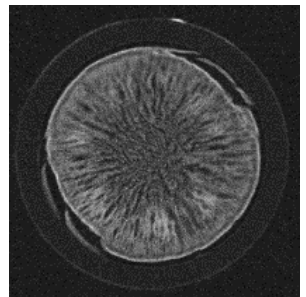

$7 \mathrm{~mm}$

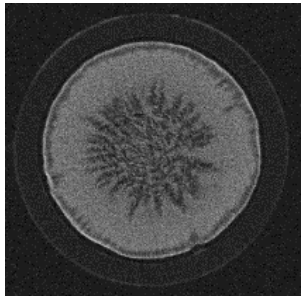

$5.7 \mathrm{~mm}$

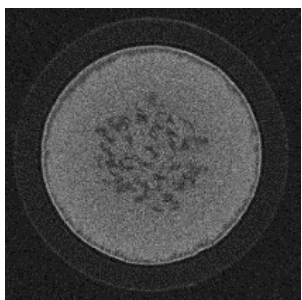

$3.2 \mathrm{~mm}$

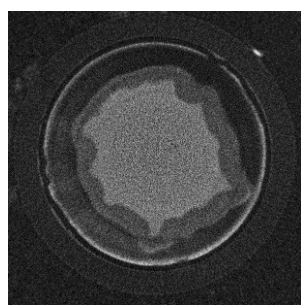

$0.2 \mathrm{~mm}$

Figure 5. Series of horizontal cross-sectional slices of the tomographic volume reconstruction at different heights. The given positions are measured from the footprint of the sample.

In brief, Figure 5 also indicates a complex drying process in the vertical direction. The different dry fractions, corresponding to the dark-gray regions, vary strongly in the vertical direction. As can be identified, the fraction of dry fingers in the center of the sample is larger at the top side of the sample 
(at higher position), whereas only a few fingers penetrate the sample to the bottom. Thus, Figure 5 reveals the formation of transient regions where the above definition of drying zones (in horizontal direction) is expected to change with drying time.

The height-dependent saturation of the sample can be estimated from the horizontal image stack shown in Figure 5. It is defined as the ratio of the sum of all white pixels of each image to the total number of pixels of the regarded image. The result is shown in Figure 6. The saturation was calculated from the tomography images after binarization with a global threshold of 0.4. Following discussions referring to the shape of the sample and shrinkage during drying, some bottom and top layers were excluded from this estimation (refer also to Figure 5). Precisely, the upper approximately $4.2 \mathrm{~mm}$ of the sample is not analyzed in Figure 6; from the lower part, $0.72 \mathrm{~mm}$ (measured from the footprint of the sample) was excluded. According to this, the curve in Figure 6 represents only the cylindrical part of the sample between these positions. This is illustrated by the figure insets.

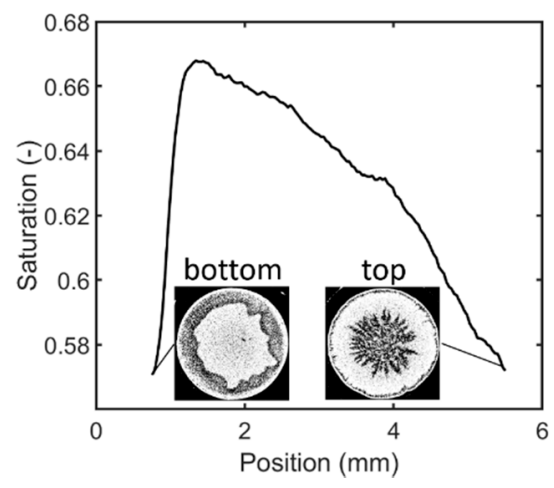

Figure 6. Variation of the saturation with height of the sample after $11.5 \mathrm{~h}$ of drying. The image at the bottom side refers to position $0.72 \mathrm{~mm}$, and the image at the top side refers to position $5.47 \mathrm{~mm}$ (measured from the sample footprint). In total, 138 images were considered (with distance $0.0344 \mathrm{~mm}$ between them).

As can be seen, the saturation decreases almost linearly with height over most of the evaluated part of the sample. A peak with maximum water content is found at position $1.4 \mathrm{~mm}$. Left from the peak, the saturation also decreases toward the bottom side. As shown by the inset, the bottom side dried mainly peripherally. The different slopes of the two branches of the curve indicate that drying mainly proceeded from the top side. The bottom side instead remained connected to the drying chamber wall in the center of the sample, from where the heat for sublimation was supplied. As a result, the top side had approximately the same saturation as the bottom side, although very different drying behavior is revealed by the inset images in Figure 6 .

\subsection{Discussion}

The development of sublimation zones was already described in Reference [34], where brick and glass bead beds were studied. Here, the deviation from the flat front was explained by the increase in temperature and the presence of a heterogenous pore structure in the packed beds, i.e., with regions of primarily smaller or larger pores. This explanation becomes reasonable if the drying of the regions with larger pores is assumed to be limited by heat transfer mechanisms. Thus, when the heat flux was increased by higher temperature gradients, more water could most probably be sublimed and removed from the larger pores. In the regions with smaller pores, mass transfer would have instead been limited, resulting in some pore ice remaining. A similar explanation would hold for our observations if it is assumed that the pore size distribution was heterogeneous with larger pores in the center and smaller pores at the periphery of the sample.

Following References [21,24,35-38], the freezing process is responsible for the porous structure of the frozen dry cake, as this is formed by the ice crystals of water and the freeze concentration of 
maltodextrin around the ice crystals. Understandably, smaller ice crystals can form smaller pores, whereas larger pores are a result of large ice crystals. Consequently, the most important parameters for the formation of the pore structure are related to the crystallization process during the freezing step prior to drying. In addition to the solid concentration and temperature, the available number of nuclei, the degree of supercooling, the mobility of the water molecules, and the freezing rate also affect this process. As a rule of thumb, slow freezing occurs if the freezing rate is lower than $0.5{ }^{\circ} \mathrm{C} \cdot \mathrm{min}^{-1}$. In this situation, a lower number of nuclei result in the formation of large water ice crystals, whereas freezing rates higher than $5^{\circ} \mathrm{C} \cdot \mathrm{min}^{-1}$ are characterized by a higher number of nuclei and smaller ice crystals [6]. We did not measure the freezing rate. However, with good accuracy, we can assume that the freezing rate was initially much higher than $5{ }^{\circ} \mathrm{C} \cdot \mathrm{min}^{-1}$. We suppose that freezing of the sample occurred mainly radially from the periphery in contact with the colder wall toward the center of the cylindrical sample, as well as from the bottom side. According to Reference [35], high thermal gradients (as assumed at the start of freezing in our experiment) can result in the formation of a solidification front. Furthermore, we suppose that the freezing velocity decreased with increasing width of the propagating solid ring, as the sample-sided heat transfer coefficient and thermal conductivity impaired the solidification of the sample due to the freezing of water and maltodextrin. Such a freezing behavior can have an effect on the pore structure, such that smaller pores are located at the periphery, where the initial freezing rate is higher. Larger pores instead can be expected in the center [35,38-40] as a result of decelerating freezing velocity. As shown in Figure 7, the pore structure in our sample strongly resembles the described freezing behavior. In addition, according to Reference [24], the larger pores might have been mechanically unstable since no annealing step was provided. It could, thus, be surmised that these pores additionally widened during drying as they collapsed with each other.

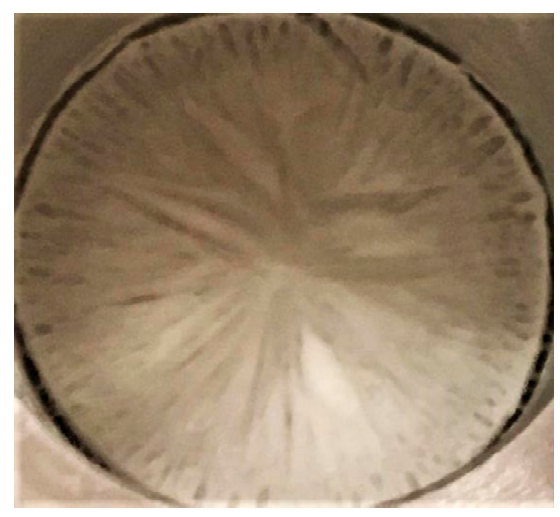

Figure 7. The photograph of the partially dried sample after $11.5 \mathrm{~h}$ (top view) reveals a star-like pore structure with long lamellar pores in the center and a rosette with smaller pores at the periphery.

The multimodal pore size distribution and the spatial variation of pore sizes can explain the observations in Figures 3 and 4. The tomographic images suggest that the center region (in dark gray) dried faster than the other regions (in light gray). The fraction of the peripheral sublimation zone appears much smaller than the fraction of the sublimation fingering zone in the sample center in these images. This could be explained with the presence of large pores in the center of the sample. Such pores would allow higher mass transfer rates and initially better heat transfer properties. The presence of large pores might have resulted in a faster progress of the sublimation front inside the individual fingers, whereas drying in the smaller pores stagnated. This is in agreement with the findings of Nakagawa et al. [24], where the larger pores were associated with the more rapid removal of water.

In summary, this outcome indicates that the intermediate shape of the sublimation front was dictated by the local drying kinetics and, thus, by the pore structure. Fractality of the sublimation front structure, as a result of the progressive invasion of the gas fingers, might have additionally been enhanced by the high heat transfer rates that were realized by the high thermal gradients. Our study is, therefore, an example of a process with extreme freezing and drying conditions, which (i) allow the 
formation of large pores, and (ii) allow much faster progression of the sublimation front inside the larger pores. As already recognized from the presented images, the demanding drying conditions can lead to a very different drying behavior than usually described in the literature. Further studies shall, therefore, consider the limits and potential of such invasion fronts.

\section{Summary and Outlook}

We showed and discussed that, with neutron imaging, structuring of the sublimation front during freeze-drying can be visualized in a fully equipped environment. The experimental set-up allowed in situ visualization of the process and revealed a complex structure of the sublimation front. We could demonstrate that the conditions for the formation of a flat sublimation front were not fulfilled in our case. Our results clearly support the findings of Nakagawa et al. [24]. Similar to Reference [24], where freeze-drying of dextrin was studied, we found that the frozen maltodextrin solution exhibited very heterogeneous drying with the result of the formation of different transient regions. This outcome was explained by the dependence of drying on the pore structure, which was a result of the freezing process prior to drying. As in Reference [24], the freezing rates were also high and annealing was omitted in our case. Furthermore, drying was conducted at relatively high temperatures. As discussed in References [24,34], such conditions are in favor for the formation of sublimation zones that deviate significantly from the simple structure of a flat front. In summary, the freezing and drying conditions resulted in penetrating dry fingers in our experiment. The dry fingers had a lamellar structure and covered the sample from top to bottom. In addition, a radial drying front was initiated along the perimeter of the sample. The tomographic images suggested that the fingers in the center of the sample dried much faster than the radial front from the perimeter.

Although the drying of a single vial was studied here, it can be expected that similar structures are likely to occur in batch processes where the freezing and drying conditions of the individual vials are usually spatially distributed. The studied example can, therefore, be seen as a starting point for the evaluation of the pore-scale processes at the limit between high drying rates and material integrity.

Similar conclusions as in this paper were drawn from neutron imaging of frozen particle beds, where several open questions were addressed in References [41,42]. On the basis of these studies, we will investigate more deeply the drying of frozen blocks and particle packings with different experimental technologies and pore network modeling [43].

Author Contributions: Conceptualization, N.V.-H. and P.F.; methodology, N.V.-H. and P.F.; software, D.M. and N.V.-H.; validation, N.V.-H. and P.F.; formal analysis, E.T. and M.S.; investigation, N.V.-H., P.F., D.M., M.H., and S.G.; resources, N.V.-H., P.F., E.T., D.M., and M.S.; data curation, D.M. and N.V.-H.; writing-original draft preparation, N.V.-H.; writing-review and editing, P.F., E.T., D.M., and M.S.; visualization, D.M. and N.V.-H.; supervision, N.V.-H., P.F., E.T., D.M., and M.S.; project administration, N.V.-H., P.F., and E.T.; funding acquisition, N.V.-H. All authors have read and agreed to the published version of the manuscript.

Funding: This research received no external funding.

Acknowledgments: We gratefully acknowledge the contributions of the student Peter Siekmann who took part in this project in the frame of his student research work.

Conflicts of Interest: The authors declare no conflict of interest.

\section{References}

1. Haseley, P.; Oetjen, G.-W. Freeze-Drying, 3rd ed.; John Wiley \& Sons Incorporated: Newark, NJ, USA, 2017; ISBN 978-3-527-34306-5.

2. Schuchmann, H.P.; Schuchmann, H. Lebensmittelverfahrenstechnik; John Wiley \& Sons: Hoboken, NJ, USA, 2012; ISBN 3527312307.

3. Pikal, M.J. Freeze Drying. In Encyclopedia of Pharmaceutical Technology, 3rd ed.; Swarbrick, J., Ed.; Informa Healthcare: New York, NY, USA, 2007; Volume 1.

4. Gehrmann, D.; Esper, G.J.; Schuchmann, H. Trocknungstechnik in der Lebensmittelindustrie; Behr: Hamburg, Germany, 2009; ISBN 3899475178. 
5. Hua, T.-C.; Liu, B.-L.; Zhang, H. Freeze-Drying of Pharmaceutical and Food Products; Elsevier Science: Burlington, VT, USA, 2010; ISBN 9781845697464.

6. Kharaghani, A.; Tsotsas, E.; Wolf, C.; Beutler, T.; Guttzeit, M.; Oetjen, G.-W. Freeze-Drying. In Ullmann's Encyclopedia of Industrial Chemistry; Wiley-VCH Verlag GmbH \& Co. KGaA: Weinheim, Germany, 2000; pp. 1-47. ISBN 9783527306732.

7. Meister, E.; Gieseler, H. Freeze-dry microscopy of protein/sugar mixtures: Drying behavior, interpretation of collapse temperatures and a comparison to corresponding glass transition data. J. Pharm. Sci. 2009, 98, 3072-3087. [CrossRef] [PubMed]

8. Meister, E.; Sasić, S.; Gieseler, H. Freeze-dry microscopy: Impact of nucleation temperature and excipient concentration on collapse temperature data. AAPS PharmSciTech 2009, 10, 582-588. [CrossRef] [PubMed]

9. Ohori, R.; Yamashita, C. Effects of temperature ramp rate during the primary drying process on the properties of amorphous-based lyophilized cake, Part 1: Cake characterization, collapse temperature and drying behavior. J. Drug Deliv. Sci. Technol. 2017, 39, 131-139. [CrossRef]

10. Nail, S.L.; Gatlin, L.A. Freeze-Drying: Principles and Practice. In Parenteral Medications; Nema, S., Ludwig, J.D., Eds.; CRC Press: Boca Raton, FL, USA, 2019; pp. 907-927. ISBN 9780429201400.

11. Schneid, S.C. Investigation of Novel Process Analytical Technology (PAT) Tools for Use in Freeze-Drying Processes; Friedrich-Alexander-University: Erlangen-Nürnberg, Germany, 2009.

12. Andrieu, J.; Vessot, S. Characterization and Control of Physical Quality Factors during Freeze-Drying of Pharmaceuticals in Vials. In Modern Drying Technology; Tsotsas, E., Mujumdar, A.S., Eds.; Wiley-VCH Verlag GmbH \& Co. KGaA: Weinheim, Germany, 2011; pp. 51-90. ISBN 9783527631667.

13. Nail, S.; Tchessalov, S.; Shalaev, E.; Ganguly, A.; Renzi, E.; Dimarco, F.; Wegiel, L.; Ferris, S.; Kessler, W.; Pikal, M.; et al. Recommended Best Practices for Process Monitoring Instrumentation in Pharmaceutical Freeze Drying-2017. AAPS PharmSciTech 2017, 18, 2379-2393. [CrossRef] [PubMed]

14. Tang, X.; Pikal, M.J. Design of freeze-drying processes for pharmaceuticals: Practical advice. Pharm. Res. 2004, 21, 191-200. [CrossRef]

15. Rasetto, V.; Marchisio, D.L.; Fissore, D.; Barresi, A.A. On the use of a dual-scale model to improve understanding of a pharmaceutical freeze-drying process. J. Pharm. Sci. 2010, 99, 4337-4350. [CrossRef]

16. Zhai, S.; Taylor, R.; Sanches, R.; Slater, N.K.H. Measurement of lyophilisation primary drying rates by freeze-drying microscopy. Chem. Eng. Sci. 2003, 58, 2313-2323. [CrossRef]

17. Li, X.; Nail, S.L. Nuclear magnetic resonance imaging of freeze-drying. J. Pharm. Sci. 2006, 95, $2516-2525$. [CrossRef]

18. Voda, A.; Homan, N.; Witek, M.; Duijster, A.; van Dalen, G.; van der Sman, R.; Nijsse, J.; van Vliet, L.; van As, H.; van Duynhoven, J. The impact of freeze-drying on microstructure and rehydration properties of carrot. Food Res. Int. 2012, 49, 687-693. [CrossRef]

19. Raman, P.; Rielly, C.D.; Stapley, A.G.F. Freeze-Drying Microscopy as a Tool to Study the Sublimation Kinetics of a Freeze-Drying Process. In Proceedings of the 19th International Drying Symposium, Lyon, France, 24-27 August 2014.

20. Siebert, T.; Zuber, M.; Hamann, E.; Baumbach, T.; Karbstein, H.P.; Gaukel, V. Micro-CT visualization of structure development during freeze-drying processes. Drying Technol. 2020, 38, 376-384. [CrossRef]

21. Wang, W.; Hu, D.; Pan, Y.; Zhao, Y.; Chen, G. Freeze-drying of aqueous solution frozen with prebuilt pores. AIChE J. 2015, 61, 2048-2057. [CrossRef]

22. Foerst, P.; Melo de Carvalho, T.; Lechner, M.; Kovacevic, T.; Kim, S.; Kirse, C.; Briesen, H. Estimation of mass transfer rate and primary drying times during freeze-drying of frozen maltodextrin solutions based on X-ray $\mu$-computed tomography measurements of pore size distributions. J. Food Eng. 2019, 260, 50-57. [CrossRef]

23. Handbook of Industrial Drying, 4th ed.; Mujumdar, A.S. (Ed.) CRC Press: Boca Raton, FL, USA, 2015; ISBN 9781466596658.

24. Nakagawa, K.; Tamiya, S.; Sakamoto, S.; Do, G.; Kono, S. Observation of Microstructure Formation During Freeze-Drying of Dextrin Solution by in-situ X-ray Computed Tomography. Front. Chem. 2018, 6, 418. [CrossRef] [PubMed]

25. Brunner, J. Quantitative Time Resolved Neutron Imaging Methods at the High Flux Neutron Source FRM-II; TU Munich: Munich, Germany, 2006.

26. Defraeye, T.; Nicolaï, B.; Mannes, D.; Aregawi, W.; Verboven, P.; Derome, D. Probing inside fruit slices during convective drying by quantitative neutron imaging. J. Food Eng. 2016, 178, 198-202. [CrossRef] 
27. Mannes, D.; Schmid, F.; Wehmann, T.; Lehmann, E. Design and Applications of a Climatic Chamber for in-situ Neutron Imaging Experiments. Phys. Procedia 2017, 88, 200-207. [CrossRef]

28. Defraeye, T.; Aregawi, W.; Saneinejad, S.; Vontobel, P.; Lehmann, E.; Carmeliet, J.; Verboven, P.; Derome, D.; Nicolaï, B. Novel Application of Neutron Radiography to Forced Convective Drying of Fruit Tissue. Food Bioprocess Technol 2013, 6, 3353-3367. [CrossRef]

29. Goff, J.A.; Gratch, S. Low-pressure properties of water from $-160^{\circ}$ to $212^{\circ}$ F. Trans. Amer. Soc. Heat Vent. Eng. 1946, 52, 95-121.

30. Kaestner, A.P.; Hartmann, S.; Kühne, G.; Frei, G.; Grünzweig, C.; Josic, L.; Schmid, F.; Lehmann, E.H. The ICON beamline-A facility for cold neutron imaging at SINQ. Nuclear Instrum. Methods Phys. Res. Section A Accel. Spectrometers Detect. Assoc. Equip. 2011, 659, 387-393. [CrossRef]

31. Siegwart, M.; Harti, R.P.; Manzi-Orezzoli, V.; Valsecchi, J.; Strobl, M.; Grünzweig, C.; Schmidt, T.J.; Boillat, P. Selective Visualization of Water in Fuel Cell Gas Diffusion Layers with Neutron Dark-Field Imaging. J. Electrochem. Soc. 2019, 166, F149-F157. [CrossRef]

32. Blau, B.; Clausen, K.N.; Gvasaliya, S.; Janoschek, M.; Janssen, S.; Keller, L.; Roessli, B.; Schefer, J.; Tregenna-Piggott, P.; Wagner, W.; et al. The Swiss Spallation Neutron Source SINQ at Paul Scherrer Institut. Neutron News 2009. [CrossRef]

33. Carminati, C.; Strobl, M.; Kaestner, A. KipTool, a general purpose processing tool for neutron imaging data. SoftwareX 2019, 10, 100279. [CrossRef]

34. Toei, R.; Okazaki, M.; Asaeda, M. The stability of plane sublimation and a model of zone sublimation in freeze-drying of porous bodies. J. Chem. Eng. Japan JCEJ 1975, 8, 282-288. [CrossRef]

35. Searles, J.A.; Carpenter, J.F.; Randolph, T.W. The ice nucleation temperature determines the primary drying rate of lyophilization for samples frozen on a temperature-controlled shelf. J. Pharm. Sci. 2001, 90, 860-871. [CrossRef] [PubMed]

36. Hottot, A.; Vessot, S.; Andrieu, J. A Direct Characterization Method of the Ice Morphology. Relationship Between Mean Crystals Size and Primary Drying Times of Freeze-Drying Processes. Drying Technol. 2004, 22, 2009-2021. [CrossRef]

37. Kasper, J.C.; Friess, W. The freezing step in lyophilization: Physico-chemical fundamentals, freezing methods and consequences on process performance and quality attributes of biopharmaceuticals. Eur. J. Pharm. Biopharm. 2011, 78, 248-263. [CrossRef]

38. Pisano, R.; Arsiccio, A.; Nakagawa, K.; Barresi, A.A. Tuning, measurement and prediction of the impact of freezing on product morphology: A step toward improved design of freeze-drying cycles. Drying Technol. 2019, 579-599. [CrossRef]

39. Hottot, A.; Andrieu, J.; Vessot, S.; Shalaev, E.; Gatlin, L.A.; Ricketts, S. Experimental Study and Modeling of Freeze-Drying in Syringe Configuration. Part I: Freezing Step. Drying Technol. 2009, 27, 40-48. [CrossRef]

40. Harnkarnsujarit, N.; Charoenrein, S.; Roos, Y.H. Microstructure formation of maltodextrin and sugar matrices in freeze-dried systems. Carbohydr. Polym. 2012, 88, 734-742. [CrossRef]

41. Gruber, S.; Vorhauer, N.; Schulz, M.; Hilmer, M.; Peters, J.; Tsotsas, E.; Foerst, P. Estimation of the local sublimation front velocities from neutron radiography and tomography of particulate matter. Chem. Eng. Sci. 2020, 211, 115268. [CrossRef]

42. Foerst, P.; Gruber, S.; Schulz, M.; Vorhauer, N.; Tsotsas, E. Characterization of Lyophilization of Frozen Bulky Solids. Chem. Eng. Technol. 2020, 43, 789-796. [CrossRef]

43. Vorhauer, N.; Först, P.; Schuchmann, H.; Tsotsas, E. Pore Network Model of Primary Freeze-Drying. In Proceedings of the International Drying Symposium, Valencia, Spain, 11-14 September 2018.

(C) 2020 by the authors. Licensee MDPI, Basel, Switzerland. This article is an open access article distributed under the terms and conditions of the Creative Commons Attribution (CC BY) license (http://creativecommons.org/licenses/by/4.0/). 